\title{
Elephants and Ancients - A Case Study in Sustainable Closure Planning at the Mupane Gold Mine, Botswana
}

\author{
S. Finucane URS Australia Pty Ltd, Australia \\ R. Gallinger IAMGOLD Corporation, Canada
}

\section{INTRODUCTION}

The Mupane Gold Mine (Mupane) is located $30 \mathrm{~km}$ southeast of Francistown, close to the border between Botswana and Zimbabwe (Figure 1). The mine is operated by Mupane Gold Mining (Pty) Ltd (MGM), a subsidiary of Toronto-based IAMGOLD Corporation. Although the site was only opened in February 2005 and operations are expected to continue for another seven years, considerable work has already gone into planning for the site's closure. This has occurred because MGM recognises that mine closure not only needs to involve rehabilitation, but increasingly needs to address ongoing environmental and socio-economic issues. This paper describes the key issues associated with sustainable mine closure planning at Mupane.

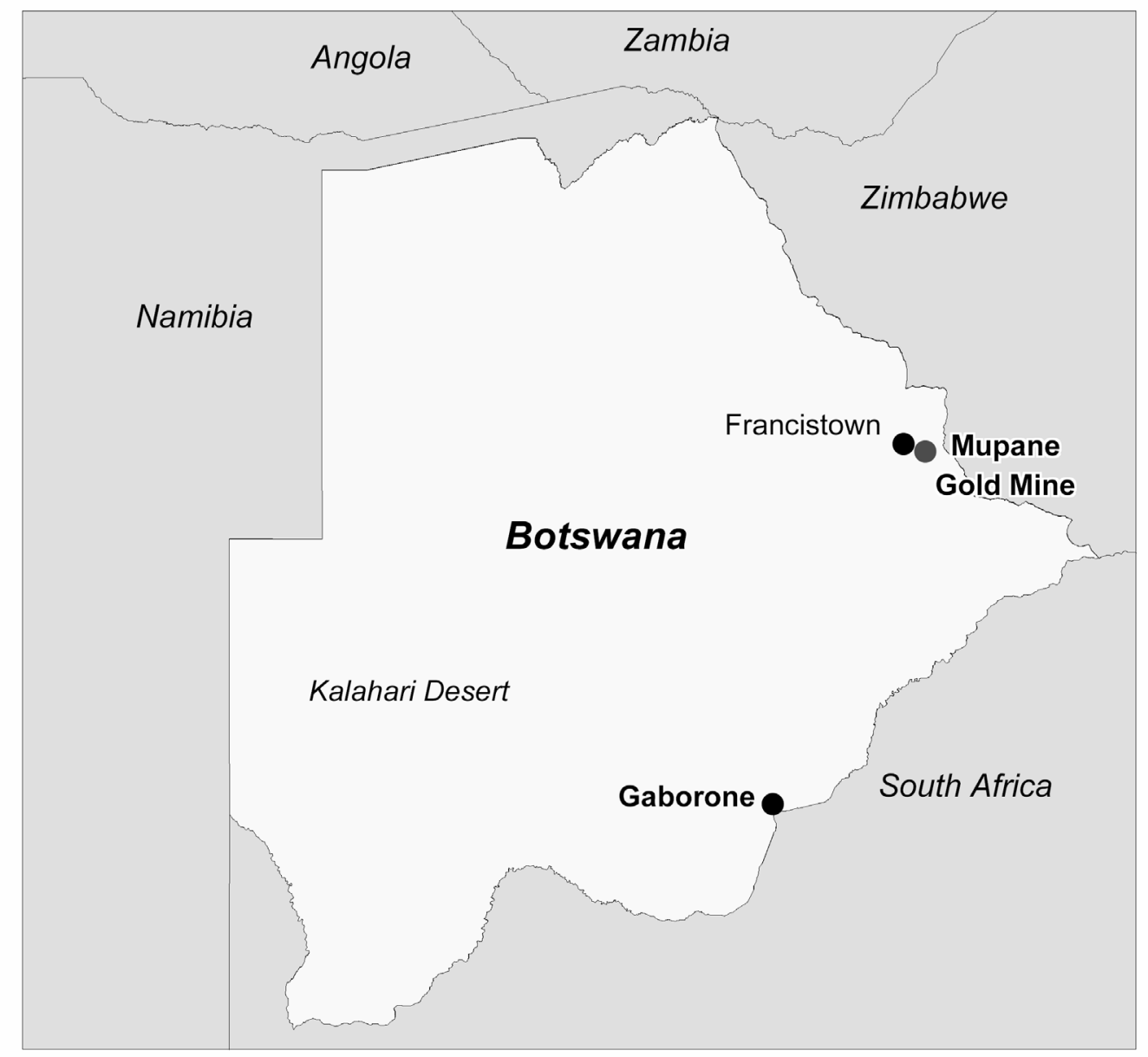

Figure $1 \quad$ Location map 


\section{BACKGROUND}

The Mupane prospect was discovered in 1998 during a systematic regional gold exploration programme in the Tati greenstone belt. Drilling campaigns were conducted over subsequent years, with work on a definitive feasibility study commencing in April 2002. In May 2003, an Environmental Impact Statement (EIS) was completed and submitted to the Botswana Government for review. In September 2003, the Government approved plans for the project and the Mupane mining lease was granted to MGM. Construction of the processing plant was initiated in October 2003, with mining commencing in May 2004.

Mupane was officially opened in February 2005 by Botswana's President, Mr Festus Mogae, and is designed to produce $100000-120000$ ounces of gold per annum. Currently, open cut mining is conducted at the Tau and Tholo pits, and mining is planned at three additional pits (Kwena, Signal Hill A and Signal Hill B). Ore from the pits is hauled to the Run of Mine (ROM) Pad before being crushed and conveyed to the processing plant. Waste rock dumps have been developed adjacent to the Tau and Tholo pits, and progressive rehabilitation of the Tau waste dump has commenced.

Processing of the ore is conducted using conventional carbon-in-leach technology. A flotation circuit was added to the one million tonne per annum plant early in 2006 to treat sulphides in ore from the Tau pit. Tailings are deposited in a circular Tailings Storage Facility (TSF) located west of the processing plant. A ferric sulphate solution is added to the tailings prior to discharge to the TSF to reduce the concentration of arsenic and cyanide in the tailings material.

\section{ENVIRONMENTAL AND SOCIAL SETTING}

Mupane is located in the North East District of Botswana, in a semi-arid region with an average annual rainfall of $460 \mathrm{~mm}$ (Mafa, 2003). The rainfall pattern varies both seasonally and annually, but in most years rain occurs between November and February. The average maximum temperatures range from 23 to $33^{\circ} \mathrm{C}$, with the highest temperatures recorded during October and January.

The Project Area comprises relatively flat land, with a few low hills. Very limited groundwater and no permanent surface water occur in the Project Area. Drainage lines tend to be shallow and ephemeral, and no major rivers occur in the Project Area. The vegetation is dominated by mopane woodland and shrub savanna, along with acacia woodlands. Wildlife in the area includes steenbok, impala, duiker, kudu, jackal, hyena and leopard.

The North East District of Botswana consists primarily of freehold farms and tribal land, with only a small proportion being State land (Geoflux, 2003). Prior to the establishment of the Mupane mining lease, the land was held as freehold land.

Land around the Project Area is used for game ranches and farming. Other land uses in the vicinity of the mine include copper/nickel mining. The major regional centre is Francistown, which is located approximately $30 \mathrm{~km}$ northwest of Mupane. A number of villages such as Mathselagabedi and Matsiloje occur closer to the Project Area. Population density in Francistown is approximately 30 people per square kilometre, but in the vicinity of the Project Area there is around only one person per square kilometre.

\section{THE CLOSURE PLANNING PROCESS}

It is widely recognised that planning for progressive rehabilitation and site closure should be an integral component of overall mine planning. The importance of this is captured in the Strategic Framework for Mine Closure, published by the Australian and New Zealand Minerals and Energy Council (ANZMEC) and the Minerals Council of Australia (MCA) in 2000, which describes mine closure as:

“... a continuous series of activities that begins with pre-planning prior to the project's design and construction, and ends with the achievement of long-term site stability and the establishment of a self-sustaining ecosystem..."

More recently, the Environment Security initiative (Peck, 2005) recommended that the mine closure plan be an integral part of the project life cycle and be designed to ensure that: 
- The post-mining use of the site is beneficial and sustainable in the long-term.

- Environmental resources are not subject to physical and chemical deterioration.

- Future public health and safety are not compromised.

- Any adverse socio-economic impacts are minimised.

- All socio-economic benefits are maximised.

Closure planning for Mupane commenced during the environmental impact assessment phase. The EIS outlined the closure objectives for the site and a preliminary closure design was included in the Environmental Management Plan appended to the EIS. Whilst these documents provide an outline of closure requirements for the site, MGM recognised the need to integrate closure planning into the mine life cycle, and initiated more detailed closure planning the same year that the project was opened. This work resulted in the development of a preliminary closure cost estimate based on a conceptual closure design. This design was based on a nominated post-operational land use of farmland for the grazing of domestic stock and wildlife (for game ranching).

Preparation of a Conceptual Closure Plan also commenced in late 2005, and was followed by a closure cost estimate review in early 2006. The review process included an on-site workshop attended by representatives of MGM, URS Australia Pty Ltd and the site mining contractor during which many aspects of the closure design and assumptions made in estimating closure costs were "challenged" by the study team and alternative approaches were discussed. This provided a greater understanding of where additional data were required to further refine the closure design and costs.

Mupane's closure plan will evolve with the operation. Modifications will be made as new issues are identified, new closure alternatives are discovered or site experience in closure implementation improves.

\section{$5 \quad$ CLOSURE ISSUES}

\subsection{Overview}

Based on closure planning conducted to date, it is considered that the key issues associated with sustainable mine closure planning at Mupane include:

- How can the lack of legislation regarding site closure be addressed?

- What are appropriate completion criteria, and how can these be developed when faced with a lack of guidance from regulators and a local community not familiar with this process?

- Who are the stakeholders in mine closure, and how should they be engaged?

- How can a "culture of dependence" be avoided if local communities become reliant on the mine for the income, employment, infrastructure and facilities provided through the mine? How can the socio-economic impacts of site closure be managed and minimised?

- How should pre-existing disturbances and legacies be addressed, particularly if these are ancient workings more than 1000 years old? How can heritage sites be sustained during and following closure?

- How can the site be made safe in the long-term for people and wildlife (including elephant, kudu and flamingo)?

These issues are discussed below.

\subsection{Legal and Other Requirements}

Issue: How can the lack of legislation regarding site closure be addressed?

Historically speaking, the lack of "designing for closure" continues to be an issue for older mines and abandoned mines worldwide. By example, North American mines that operated and closed through to the 1950s probably did so under full compliance. However, little or no thought was given to the future, and 
these sites can have serious safety and water quality issues associated with them. Rehabilitation of these historical sites is generally far more expensive than if the site had been designed with closure issues in mind. Governments who have recognised the liability associated with poor mine closure planning have reacted by enacting legislation to prevent the future public liabilities, as well as address the current ones.

Where there is a lack of legislation regarding site closure, it is often left to the individual companies to set their own standards and develop their own plans for sustainable mine closure. In developing the Mupane Conceptual Closure Plan, relevant legislation, mining lease conditions and industry guidelines were considered.

In Botswana, the revised Mines and Minerals Act (1999) requires that mining companies develop proposals for closure and rehabilitation of mine sites and related facilities for consideration and approval by the director of the Department of Mines. The proposals should, as a minimum, aim to make workings and facilities safe and restore the environment to as close as possible its natural state (Geoflux, 2003). The lack of detail and guidance on what is acceptable can be both an obstacle and an opportunity. This has been addressed at a conceptual level through the development of preliminary completion criteria (see Section 5.3).

Early definition of the landholders' requirements for site rehabilitation and closure assists in addressing some of the challenges posed by limitations in government guidance on acceptable standards for site closure. Mupane is covered by two Notarial Mineral Leases which include conditions relating to mine closure. These conditions were negotiated with the landholders and address such aspects as the removal of certain project infrastructure, the retention of other infrastructure such as water pipes and pumps, and the disposal of waste materials. It is considered that having these agreements in place will facilitate relinquishment of the mining leases and return of the site to the landholders.

In the absence of detailed legislation or documented government requirements, it is often industry guidelines that serve as a framework for mine closure planning. In preparing the Mupane Conceptual Closure Plan, reference was made to a range of guidelines such as those developed by the World Health Organisation and United Nations Environment Programme (1998), ANZMEC and MCA (2000, 2003) and the International Council on Mining \& Metals (2005).

In countries where there is no detailed legislation for mine closure, challenges including obtaining Government agency approval for closure planning and relinquishing the site once rehabilitation is complete. These two aspects can be elusive, even in highly regulated countries. The key to success is involving all stakeholders throughout the process and ensuring that expectations are clear and understood (see Section $5.4)$.

\subsection{Developing Completion Criteria}

Issue: What are appropriate completion criteria, and how can these be developed when faced with a lack of guidance from regulators and a local community not familiar with this process?

Completion criteria are an agreed set of indicators which, upon being met, would demonstrate that the site has been decommissioned, rehabilitated and closed successfully. Completion criteria are specific to individual operations, and should reflect the unique set of environmental, social and economic conditions at the site. Where possible, the criteria should be quantitative and capable of verification.

Developing appropriate completion criteria is critical to the closure planning process but often one of the most difficult aspects. Inexperienced (and even experienced) regulators are often reluctant to provide guidance on what they would consider to be acceptable completion criteria. It can also be difficult to engage the local community in discussions on completion criteria, especially if they are not familiar with this type of process.

With these issues in mind, MGM proposes to develop its completion criteria in three stages:

- Development of draft criteria to guide the initial (conceptual) phases of closure planning.

- Consultation with key stakeholders to establish agreed preliminary criteria.

- Finalisation of criteria that have been agreed to, and are supported by, regulatory authorities and other relevant stakeholders. 
Draft completion criteria were developed in 2005 during the development of the Conceptual Closure Plan, and are outlined in Table 1.

\section{Table $1 \quad$ Draft completion criteria}

\begin{tabular}{|c|c|}
\hline Closure Issue & Completion Criteria \\
\hline Safety & $\begin{array}{l}\text { The site will be left tidy and safe, with public safety risks defined and } \\
\text { reduced to acceptable levels. } \\
\text { Access to site will be restricted, appropriate to the post-mining land use. } \\
\text { All drill holes, shafts and other openings will be securely capped, filled or } \\
\text { otherwise made safe. }\end{array}$ \\
\hline $\begin{array}{l}\text { Stability of } \\
\text { Landforms and } \\
\text { Surfaces }\end{array}$ & $\begin{array}{l}\text { All constructed landforms and disturbed areas will be stable and resistant to } \\
\text { erosion or at least comparable to background erosion for the area. } \\
\text { Drainage will be consistent with the post-mining land use, where possible. }\end{array}$ \\
\hline Infrastructure & $\begin{array}{l}\text { Infrastructure to remain on site will be agreed with the landholder. All } \\
\text { remaining infrastructure will be demolished, dismantled and disposed of for } \\
\text { use elsewhere, sold off as scrap or be buried on site. }\end{array}$ \\
\hline Re-vegetation & Rehabilitated areas will be revegetated to a self-sustaining condition. \\
\hline $\begin{array}{l}\text { Landform } \\
\text { Reconstruction }\end{array}$ & $\begin{array}{l}\text { The landform design will be compatible with the post-mining land use and } \\
\text { adjacent landscape. } \\
\text { Final landforms will not be a source of erosion or dust generation. }\end{array}$ \\
\hline Water Quality & $\begin{array}{l}\text { The quality of the surface water and groundwater resources leaving the site } \\
\text { will be such that it conforms to appropriate quality criteria. }\end{array}$ \\
\hline Soil & $\begin{array}{l}\text { The quality of the soil remaining at site will be safe and compatible with } \\
\text { the final land use and landowner agreements. }\end{array}$ \\
\hline Visual Amenity & $\begin{array}{l}\text { The final landform design will be compatible with the post-miningland use } \\
\text { and adjacent landscape. } \\
\text { Final landforms will not be a source of erosion or dust generation. } \\
\text { No rubbish will remain at surface, or be at risk of being exposed through } \\
\text { erosion. }\end{array}$ \\
\hline Sustainability & $\begin{array}{l}\text { The site will not require active management beyond agreed maintenance } \\
\text { requirements. }\end{array}$ \\
\hline Legal & $\begin{array}{l}\text { All site activities and closure requirements will be implemented in } \\
\text { accordance with applicable legal requirements. }\end{array}$ \\
\hline
\end{tabular}

These draft criteria are general and were prepared based on known issues. The next steps are to refine these criteria in consultation with MGM's stakeholders, address issues pertinent to stakeholder interests and further define the criteria in specifics that are measurable, realistic and achievable. 


\subsection{Stakeholder Identification and Engagement}

Issue: Who are the stakeholders in mine closure, and how should they be engaged?

Stakeholder consultation is an important component of planning and implementing mine closure. It involves engaging all organisations, individuals and other parties that could potentially be affected by site closure. In addition, consultation may occur with those parties that are interested in, but are not directly or indirectly affected by, site closure.

The objectives of MGM's stakeholder engagement programme in relation to site closure planning are to facilitate the transfer of information between the company and its stakeholders, and to ensure that relevant stakeholders interests are given adequate consideration. A preliminary list of stakeholders has been prepared and includes government at a national, regional and village level as well as non-government organisations, local communities and individuals.

MGM commenced the consultation process during the preparation of the Project's EIS. As closure planning progresses, information about the process will be provided to the stakeholders and discussions will be held in relation to a range of closure issues. MGM recognises the importance of initiating these discussions as early in the planning process as possible to allow maximum time for resolution of any technical, legal, environmental and social issues. The procedure for mine closure and transfer of land can be complex and it's important to allow sufficient time to clearly define these processes, particularly when dealing with groups that have not been through this process before, where administrative procedures are unclear or absent, and where the responsibilities of all parties are still to be clearly and comprehensively defined.

Modifications to the Closure Plan will be made in response to input from the stakeholders and regular updates will be provided on the outcomes of the closure planning process.

\subsection{Avoiding a Culture of Dependence}

Issue: How can a "culture of dependence" be avoided if local communities become reliant on the mine for the income, employment, infrastructure and facilities provided through the mine? How can the socioeconomic impacts of site closure be managed and minimised?

Mining is a temporary land use which often provides a high level of economic return for local communities and can trigger local and regional development (Robertson, 2004). In some instances, communities can become dependent on a mining project for income through direct employment, and/or the provision of supplies and services. In addition, remote communities often rely on mining companies to provide infrastructure such as water and power supplies, and other assistance. Consequently, closure of a mining operation can result in loss of income and other services. Therefore, it is important for closure planning to address the socio-economic impacts of mine closure and the impact on workers and their families, communities and the local economy.

MGM is committed to using a local workforce and service providers where practicable, but no community is solely reliant on the project for income or other support. However, loss of jobs and service contracts will inevitably occur when the mine closes. To offset this, MGM has developed a training programme that has been accredited by the Botswana Government (specifically, the Botswana Training Authority). The training received by workers at MGM will meet the country requirements for transferring to other employment. Workers will be able to reference the training gained at MGM and build upon this training to further advance their skills and level of employment. The accredited training is also recognized in other countries.

Meetings are held with employees, neighbours and other stakeholders to advise of the progress of the operations and to listen to all concerns. The intent is to communicate the status of project activities, but to also ensure that everyone's expectations regarding project operations and closure are realistic.

\subsection{Managing Heritage Sites}

Issue: How should pre-existing disturbances and legacies be addressed, particularly if these are ancient workings more than 1000 years old? How can heritage sites be sustained during and following closure? 
Reference to historical mining disturbances typically brings to mind abandoned sites where unplanned or poor closure practices have resulted in unsafe workings, unrehabilitated or unremediated land, and ongoing sources of pollution. However, the area around Francistown and Mupane contains numerous old "abandoned" gold mines which were probably mined both in prehistoric times and by early European miners, some of which may be historically significant.

From about 1000 to about $1400 \mathrm{AD}$, the Leopard's Kopje chiefdom in northeastern Botswana and the Matopos area included a high density of settlements and large cattle kraals, suggesting that relatively large human and livestock populations occurred in the region at that time. Gold mining probably started in this region around 1200AD, with sites located primarily on hills (van Waarden, 2000).

Towards the end of the $13^{\text {th }}$ century, certain areas became uninhabitable as the climate became drier but it appears that the gold mines of the northeastern region continued to keep people in the region. Gold mining probably continued in the area on a relatively small scale until a gold rush in $1869-1872$ resulted in European settlement along the Tati River, in an area now known as Old Tati, and the development of many mines. The Tati settlement was replaced by Francistown in 1897 (van Waarden, 2000).

Eleven archaeological sites have been recorded in the vicinity of the Mupane mine. Most of these sites comprise terraces and walling, but one of the sites may have been a prehistoric gold or iron mine which could date back as early as the Leopard's Kopje period. If this is the case, the site could be of importance as most of the prehistoric mines in the region were destroyed during subsequent European mining. This site is located in the vicinity of one of the proposed mine pits, so MGM is conducting further work to determine whether the site is a prehistoric mine and what protection and management it may require.

One of the other archaeological sites at Mupane occurs in the vicinity of an active mine pit. This site comprises extensive walling on and around the top of a hill, a portion of which is being mined by MGM. Extensive work was conducted to determine any risks to the site if mining proceeded, and the site has been monitored carefully during the mining operations. To date, no impacts on the site have been recorded.

Whilst protecting archaeological sites in the Mupane Project Area does not cause any particular problems during operations, the same degree of protection may not be feasible following site closure. This issue has been identified in the site's Conceptual Closure Plan as one which requires further investigation, including consultation with Botswana's National Museum.

\subsection{Long-term Management of Risk}

Issue: How can the site be made safe in the long-term for people and wildlife?

In general, mining companies recognise the importance of understanding the beneficial and adverse impacts that their activities can have on the natural and social environments in which they operate. However, it is equally important to understand how these impacts will change as a result of site closure, and what is required to eliminate, minimise or manage significant long-term risks. This can of course be difficult when operating in countries in southern Africa where rehabilitation technologies and closure strategies are often still to be validated scientifically in a local context. However, approaches to achieving success have been tested in other locations in the world which provides confidence in local application.

Returning the land to a suitable land use is the goal of mine closure and can be truly measured as achieved when the completely rehabilitated mine has reached a state where the landholder accepts responsibility for the land and mining leases can be relinquished. Landholders (including Governments) can be reluctant to accept transfer of the site where there is a significant risk of physical instability (e.g. where pit walls or waste dump slopes could fail) or chemical mobility (such as the leaching of contaminants from a TSF). Consequently, ongoing environmental and social risk assessments are an important part of closure planning (Figure 2). 


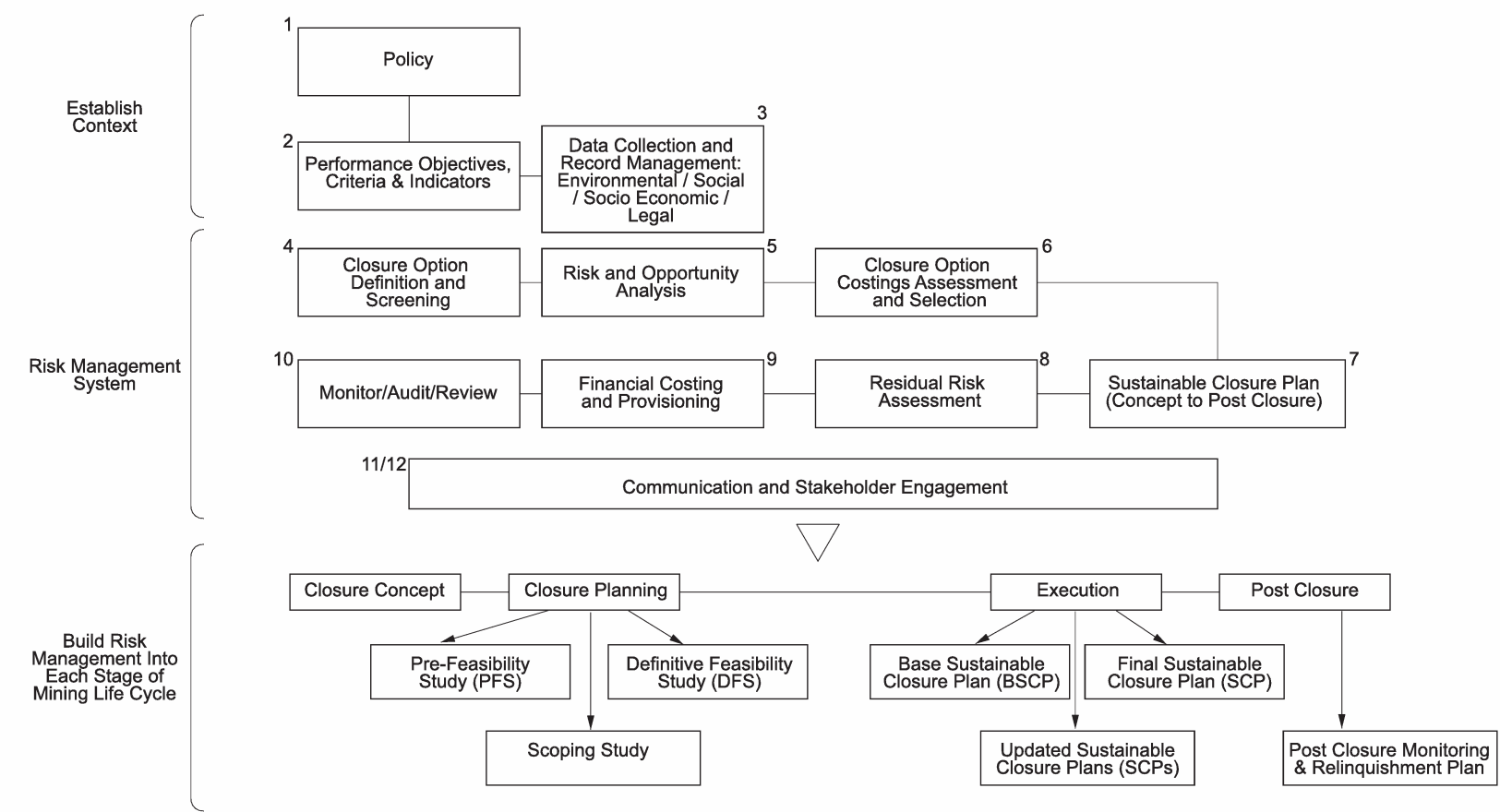

\section{Figure 2 Risk management during mine closure planning}

Risks associated with past, present and future mining and processing activities must be understood if a closure plan is to be effective and liabilities are to be reduced. To facilitate this at Mupane, the aspects and impacts associated with mine closure were included in the site's Environmental Risk Register. As the register is reviewed and updated, the risk profile on which the Closure Plan is based will be modified. This allows implementation of measures to prevent impacts from occurring or to mitigate or manage those impacts that do occur. These measures need to be appropriate to the site's environmental and social characteristics. For example, fencing is often installed at the entrance of an abandoned open pit and, on occasions around a pit, to prevent entry by the public and wildlife. However, in developing areas there is a significant risk that the fencing will be stolen so alternative ways of preventing access need to be identified. Further, fencing is often ineffective in preventing access by larger and more mobile species such as kudu (a large antelope) and elephant. Therefore, alternative measures will be required.

An ongoing risk assessment process also allows the development of realistic closure standards and completion criteria, in consultation with stakeholders. It is also important that the consultation programme disseminates information on, and ensures that relevant stakeholders (such as the landholder and local communities), understand any risks that may exist at the site in the long-term. As indicated previously, sufficient time needs to be allowed for technical investigations and stakeholder liaison to resolve the management of any residual risks.

\section{CONCLUSION}

For mine closure planning to be effective, it needs to consider a wide range of issues, which can be as disparate as elephants and "ancients" (representing heritage sites more than 1000 years old).

Closure is an iterative process that can evolve over the life of mining. Designing for closure is key and incorporating the thinking around risk management for post-closure will help to eliminate the potential for future legacies. Proper engineering, testing rehabilitation strategies, implementing closure design through the operations, and involving stakeholders in the process contribute to a successful outcome. By incorporating these principles into MGM closure planning and implementation, it is expected that closure will be successful. 


\section{REFERENCES}

Australian and New Zealand Minerals and Energy Council and Minerals Council of Australia (2000) Strategic Framework for Mine Closure. Canberra, Australia.

Australian and New Zealand Minerals and Energy Council and Minerals Council of Australia (2003) Strategic Framework for Tailings Management. Canberra, Australia.

Geoflux (Pty) Ltd (2003) Environmental Impact Assessment for the Proposed Mupane Gold Mine. Environmental Impact Statement. Prepared for Gallery Gold Botswana. May 2003.

International Council on Mining \& Metals (2005) Financial Assurance for Mine Closure and Reclamation.

Mafa, B. (2003) Environmental Hydrogeology of Francistown: Effects of Mining and Urban Expansion on Groundwater Quality. Department of Geological Survey Botswana. March 2003.

Peck, P. (2005) Mining for Closure. Report prepared on behalf of the Environment and Security Initiative. United Nationals Environment Programme. June 2005.

Robertson, A. (2004) The Six Tenets of Sustainability for Mining. http://www.infomine.com/technology/enviromine/issues/sustain_tenets.html. Accessed 18 April 2004.

van Waarden, C. (2000) Mpanipani Hills Prospecting Area Archaeological Impact Assessment. Report prepared for Gallery Gold Botswana (Pty) Ltd, February 2000, and presented as Appendix 3.4 in Geoflux (Pty) Ltd, 2003.

World Health Organisation and United Nations Environment Programme (1998) Mine Rehabilitation for Environment and Health Protection - A Training Manual. 